\title{
Determinants of information system quality and data quality in management accounting
}

\author{
${\text { Thorsten } \text { Knauer }^{1} \text { (D) } \cdot \text { Nicole Nikiforow }^{1} \text { (D) } \cdot \text { Sebastian Wagener }}^{1}$ (D)
}

Published online: 18 February 2020

(C) The Author(s) 2020

\begin{abstract}
Data quality is critical to adequately perform management accounting (MA) tasks, and information systems (IS) provide the data for the MA domain. However, IS can vary vastly across firms, which may influence the basis for rational decision making (i.e., data quality). This study therefore aims to investigate the impact of IS quality on data quality in MA and to analyze the determinants that can influence IS quality in MA. We conduct a cross-sectional survey among 143 medium-sized and large firms. Based on a structural equation model, we predict and find that IS quality significantly affects management accounting data quality (MADQ). Company's IT investments, internal and external IT knowledge, innovative technologies, and data source variety are significantly associated with IS quality in MA and in turn indirectly affect MADQ. This study highlights the importance of IS quality for management accountants' practice and simultaneously provides new insights regarding the efficacy of selected determinants of IS quality.
\end{abstract}

Keywords Data quality · Information systems · Information technology · Management accounting $\cdot$ System quality

JEL Classification M15 - M41

Electronic supplementary material The online version of this article (https://doi.org/10.1007/s0018 7-020-00296-y) contains supplementary material, which is available to authorized users.

Sebastian Wagener

sebastian.wagener@rub.de

Thorsten Knauer

thorsten.knauer@rub.de

Nicole Nikiforow

nicole.nikiforow@rub.de

1 Ruhr-Universität Bochum, Universitätsstr. 150, 44801 Bochum, Germany 


\section{Introduction}

Data are the foundation of management accountants' practice. Traditionally, the role of management accounting (MA) in organizations has been limited to providing information to support decision-making (Scapens and Arnold 1986). Driven by advances in information technology (IT), the modern understanding of management accountants' role is more extensive and tends towards model development, consultation, and interpretation (Booth et al. 2000; Caglio 2003). Simultaneously, IT developments have altered the origin of MA data. Nowadays, information systems (IS) constitute the primary source of data for management accountants' work, improving the availability of data (Burns and Scapens 2000).

IS are operated throughout organizations due to their ability to collect, store, organize, process, and distribute large volumes of data (Beard and Sumner 2004). Management accountants are thus able to gather, merge, and interpret data from very different sources (Richins et al. 2017). Moreover, a substantial number of IS developments specifically aim to fit and automate MA techniques that analyze data (Rom and Rohde 2007). Being an integral part of MA, IS and MA should therefore be jointly studied (Dechow and Mouritsen 2005). In organizational practice, rather than questioning IS data, the data output is usually regarded as given; thus, managers often "blindly" rely on accounting numbers (Quattrone 2016). However, IS quality in MA varies widely and may thus determine the extent to which the data meet management accountants' information requirements, which we refer to as management accounting data quality (MADQ).

In this study, we draw on the findings of Gorla et al. (2010) and argue that investigating IS quality in MA can significantly enhance our understanding of MADQ. Specifically, we predict that IS quality in MA is positively associated with MADQ. Further, the study aims to analyze factors that affect IS quality in MA and in turn MADQ. In selecting the determinants, we build on the insights of the literature on the resource-based view of IS, while taking new technological developments into consideration. In particular, we expect that a company's IT investments, internal and external IT knowledge, and the application of innovative technologies increase the quality of IS in MA. We further suggest that incorporating different data sources with different quality characteristics (e.g., financial information vs. social media information) into IS increase complexity and thus impairs IS quality.

We develop and test a structural equation model (SEM) using data from a cross-sectional survey with 143 respondents that provide insights into IS in MA of medium-sized and large companies. We use a multidimensional construct that characterizes IS quality in terms of ease of use, access and computation time, integration, automation, and flexibility. While prior literature tends to neglect the role of automation, our study adds this dimension to the IS quality construct due to its assistance in supplying data of constant quality and relieving the burden on employees (Bravo et al. 2016).

The findings from the structural model support the hypothesized associations. In particular, we find that increasing levels of IS quality in MA improve MADQ. Further, the results indicate direct associations of the examined determinants-IT 
investment, internal IT knowledge, external IT knowledge, innovative technologies, and data source variety-with IS quality in MA. All associations are positive, except for source variety, which is negatively associated with IS quality in MA. Additionally, external IT knowledge shows a direct effect on MADQ. Mediation analysis further confirms indirect effects of the IS quality determinants examined on MADQ. Accordingly, we conclude that the investigated determinants of IS quality show the potential to affect MADQ indirectly through IS quality in MA.

This study contributes to the literature on MA and IS in several ways and has important implications for management accountants. First, we extend the literature by drawing attention to the relevance of IS quality for MA practice. Notably, IS quality directly affects data quality and mediates the relation between IS quality factors and MADQ. Therefore, our results provide evidence that increasing IS quality in MA leads to higher data quality necessary for management accountants' tasks. In terms of evaluating IS quality, our research considers automation as an additional IS quality dimension, which has not yet been explicitly incorporated (Bravo et al. 2016). Second, our study provides insights regarding the efficacy of particular IS quality drivers in MA. While prior literature sheds some light on the effects of IS quality on data quality (e.g., Gorla et al. 2010), less attention has been paid to the determinants of IS in MA and MADQ. Hence, we deepen the understanding of the current state of IS quality in MA by documenting whether and how specific IS resources affect IS in MA. Third, we address Taipaleenmäki and Ikäheimo's (2013) call to report on changes in accounting attributable to technological developments by incorporating innovative technologies and new data sources in our model. Finally, we explore IS quality in German MA departments, validating and extending prior IS studies. Empirical research thus far has been conducted largely outside continental Europe (e.g., Asia-Pacific region, Scandinavia, and USA; Chapman and Kihn 2009; Gable et al. 2008; Gorla et al. 2010; Hyvönen 2007; Mahmood and Mann 2000; Prasad and Green 2015).

The paper proceeds as follows. Section 2 provides the theoretical background and develops the hypotheses. Section 3 discusses the research methodology, while Sect. 4 presents the results. Section 5 concludes the paper by discussing the findings and limitations.

\section{Literature review and hypothesis development}

\subsection{Information systems and data quality in MA}

IS can be defined as "a set of interrelated components that collect (or retrieve), process, store, and distribute information to support decision making and control in an organization" (Laudon and Laudon 2020, p. 48). The components in this context refer to hardware, software, people, procedures, and data (Silver et al. 1995). In organizations, IS serve a dual role (Bravo et al. 2016). On the one hand, IS are introduced to automate and operate activities amongst others in accounting and finance. On the other hand, IS facilitate the provision of data. 
In today's businesses, IS constitute the infrastructure of MA practice, representing its primary source of data. The functionality and quality of the providing system (i.e., IS quality) therefore determines the quality of data. In the context of MA, data quality (i.e., MADQ) describes the extent to which the data meet the requirements of management accountants. In other words, high quality data allows management accountants to reliably fulfil their functions, such as planning, managerial control, and decision support. There is also evidence that data quality is positively related to perceived usefulness of IS, user satisfaction (Seddon and Kiew 1994), user acceptance, and IS usage (Davis et al. 1989). Above all, data quality is regarded as a measure of IS effectiveness (Gatian 1994) and IS success in general (DeLone and McLean 1992; Gable et al. 2008). Furthermore, data quality is found to be positively related to organizational performance (Gorla et al. 2010). Overall, the potential benefits of data quality for organizations underline the importance to investigate and understand the factors that explain data quality.

\subsection{IS quality construct}

IS quality refers to the extent that the system itself is capable of performing the required tasks and is sound both from a technical and a design perspective. The conceptualization of IS quality is challenging as IS quality depends on the needs of the respective users and is subject to ongoing changes due to advances in technology and innovations (Quattrone and Hopper 2006). As a result, multiple measures of IS quality have been developed in the literature, all of which describe several interrelated dimensions (e.g., DeLone and McLean 1992, 2003). Following Gorla et al. (2010), we conceptualize IS quality in MA via two distinct dimensions: system sophistication, which represents system qualities from a user perspective, and system flexibility, which represents system qualities from a designer perspective.

The attributes commonly used to indicate system sophistication in prior research are ease of use (i.e., the level to which the system is user-friendly), access and computation time (i.e., fast or timely request responses by an application or a system), and integration (Bailey and Pearson 1983; Gable et al. 2008; Miller and Doyle 1987; Nelson et al. 2005). Integration refers to the extent to which IS facilitate the communication, transmission, and combination of data between different systems (Bailey and Pearson 1983). In general, IS integration encompasses the integration of hardware, software, and data (Booth et al. 2000).

Further, we argue that automation is a fundamental IS feature and therefore worth considering when conceptualizing IS quality. A system is considered automated if it performs functions or tasks that were previously-partially or fully-performed manually (Parasuraman and Riley 1997). Automation increases IS quality by improving system assistance. Data can be stored, retrieved, processed, and distributed without user intervention. Ideally, the resulting operations are faster, less error-prone, easier to operate, and more consistent (Bravo et al. 2016). Furthermore, automation is associated with the release of employee capacities. Considering these arguments, our study adds automation as a key element to the conceptualization of IS sophistication. In summary, the study characterizes sophisticated IS in MA as easy to use, quick-responding, integrated, and automated systems. 
Frequently changing user needs and environmental and structural uncertainties make system flexibility another critical feature of IS quality (Saraf et al. 2007). Flexibility is defined as the ability to adapt, redesign, and customize an IS application (Bailey and Pearson 1983; Nelson et al. 2005). Consequently, flexible systems are characterized by rapid and effective adjustments, the ability to incorporate unplanned requirements without replacing the entire system, and adaptability after implementation (Duncan 1995). Technically, flexibility has to be considered from the system designer perspective in IS architecture (i.e., connectivity, compatibility, and modularity; see Duncan 1995; Gable et al. 2008).

\subsection{The effect of IS quality in MA on data quality}

For our first hypothesis, we consider how IS quality in MA affects MADQ. We follow Gorla et al. (2010) and examine each IS quality dimension to determine whether it affects data quality with respect to the purposes of MA.

The integration of several IS ultimately bundles data from different areas and sources to provide a more holistic database and to improve the information content (Au et al. 2002). Operating several systems in parallel is costly, prone to errors and may cause inconsistent data and diverging results (Balkan and Goul 2010). Additionally, fragmented systems are prone to potential data breaches (Grover et al. 2018; Wang and Strong 1996). Not only does integration reduce errors and improve response times, but it also facilitates the exchange of data between business functions and units (Booth et al. 2000; Gattiker and Goodhue 2004), and contributes to the inclusion of new knowledge (Granlund 2011). ${ }^{1}$ The collection and exploitation of data are further supported by automation, which relieves the burden of daily work on management accountants (Schermann et al. 2012). Through automation, processes become both more effective and efficient (Grover et al. 2018). In this vein, automation enables faster calculation times, fewer errors, and the improved integration and coordination of databases according to system-wide standards (Häkkinen and Hilmola 2008), allowing management accountants to draw on more relevant, timely, and forward-looking information (Scapens and Jazayeri 2003). Increasing environmental volatility emphasizes the importance of system flexibility. Thus, flexible systems are easily modified and extended to meet user expectations and to ensure that MA draws on relevant data despite uncertain and changing conditions (Nelson et al. 2005).

In contrast to the aforementioned attributes of IS quality, ease of use and access and computation time do not help to perform tasks better per se. Yet, ease of use simplifies the operation of an application or a system, which, in turn, can prevent the input of erroneous data by unsophisticated users (Fox et al. 1994). User-friendliness

\footnotetext{
1 In some cases, full integration may not be possible because concurrent supplements are employed outside the system (Dechow and Mouritsen 2005). If the requirements of IS users diverge, data integration may not even be appropriate in terms of the cost-benefit ratio (Huikku et al. 2017). This applies, for example, when accounting and operational departments have to prepare forecasts with different frequencies.
} 
also increases system satisfaction and acceptance (Davis 1989). Both ease of use and fast access and computation time simplify data retrieval and improve data processing in MA.

Based on the discussion of the impact of each dimension on MADQ, we predict that the positive association between IS quality and data quality also applies to MA. The resulting hypothesis $\mathrm{H} 1$ reads as follows:

H1 IS quality in MA is positively associated with management accounting data quality.

\subsection{Determinants of IS quality}

Following the resource-based view, organizations use their capabilities and resources to create and sustain IT-related competitive advantages (Bharadwaj 2000). In line with this notion, we expect that a company's IT investments, human resources, data sources, and the technologies available to the organization play a crucial role for IS quality in MA. We elaborate on our reasoning in the following paragraphs.

\subsubsection{IT investments}

IS infrastructure must be provided either through the purchase or lease of data, systems, and technology (hardware and software). While basic IS components are affordable nowadays, recent rapid developments, for example, in data storage and processing technologies, reinforce the need for continuous costly system updates to keep up with new technology. Frequently, these developments exceed the capabilities of the present infrastructure. Thus, a flexible, integrated IS infrastructure may be required to allow the inclusion of new process designs, innovative applications, and business changes. As a result, reasonably spent investments in IT represent an essential prerequisite for operational and up-to-date IS and thus IS quality in MA (Kivijärvi and Saarinen 1995; Ragowsky et al. 2012). Following these considerations, we posit the second hypothesis:

H2 IT investments are positively associated with IS quality in MA.

\subsubsection{Internal IT knowledge}

Internal IT knowledge, which we refer to as the knowledge, skills, and abilities of a company's employees (including managers) in IT, is often viewed as an indispensable complement to financial investments in IS infrastructure (Nelson and Cheney 1987). Limited IT knowledge in organizations is a frequently cited reason for the failure of IS implementation (Nelson and Cheney 1987; Taylor and Todd 1995) and the omission of the opportunities offered by IS (Neidleman 1979). In other words, IS are either not adopted at all or the existing potential of IS within the organization is not fully exploited. Research provides evidence that employees' understanding of IS positively affects the perceived usefulness (Igbaria et al. 1995) and acceptance of the 
system (Igbaria et al. 1995; Nelson and Cheney 1987). Specifically, technical and managerial IT skills, as well as organization-specific knowledge and experience, are critical for the implementation, operation, and maintenance of IS infrastructure. It is further important that IT competencies are located not only in the IS function but also in other functional areas of the organization, such as MA (Peppard et al. 2000). Qualified employees who understand the relevant technologies can integrate IT more effectively and adapt applications in anticipation of organizational needs (Bharadwaj 2000). Thus, they are able to advance IS in MA and its MA tools (Granlund 2011), thereby increasing a system's capabilities and its quality (Rao et al. 2015).

In summary, IT-related knowledge is required to successfully operate and manage IS. It is even assumed that sufficient IS knowledge has the potential to ensure that the benefits of IS outweigh their costs (Weber 2011). Accordingly, we posit the following hypothesis:

H3 Internal IT knowledge is positively associated with IS quality in MA.

\subsubsection{External IT knowledge}

Organizations may also benefit from best practice outlines. In particular, consultants can initiate and advance IS projects within organizations (Huikku et al. 2017). In general, consultants' tasks encompass the analysis of the company's information requirements, advice on adequate hardware and software, and support in the implementation of IS (Thong et al. 1997). Consultants also assist in improving data processes and in solving data problems while consulting system users on optimal data processing and handling. Thus, external IT knowledge, which we define as knowledge provided by professional IT consultants, has the potential to complement the knowledge within the organization (Chapman and Kihn 2009). Consistent with this assumption, Gable (1991) and Kole (1983) identify the quality of external support as an important factor for IS success. Similarly, Thong et al. (1997) find a positive association between IS effectiveness and the level of external support. Igbaria et al. (1997) document that external support increases the perceived ease of use. Considering these arguments, we expect that external IT knowledge is an important driver of IS quality in MA, as reflected in the following hypothesis:

H4 External IT knowledge is positively associated with IS quality in MA.

\subsubsection{Application of innovative technologies}

Innovative technologies are constantly emerging to meet the challenges in modern businesses. Thus, the adoption of innovative technologies is considered a precondition to compete in today's economic environment (Peppard and Ward 2004). For example, the growing volume of data is likely to exceed the capabilities of conventional databases, increasing the need for organizations to update existing standards. By finding their way into organizational IS, innovative technologies allow improved data collection, storage, retrieval, processing, and transmission, thus expanding the 
analytical capabilities of MA (Bhimani and Willocks 2014). Major technological advances include online analytical processing (OLAP), cloud computing, in-memory technology, self-service reporting, and mobile technologies (e.g., Bhimani and Willocks 2014; Chen et al. 2012; Peters et al. 2016).

The benefits that organizations could derive from modern approaches-if operated successfully-are diverse and clearly technology-specific. For example, cloud computing enables organizations to manage abundant volumes of data by outsourcing data storage and performing complex computation tasks in the cloud, thereby rendering hardware expendable (Hashem et al. 2015). Data can thus be accessed and shared more cheaply and flexibly, enabling applications and technologies such as mobile services (Bhimani and Willocks 2014). Furthermore, in-memory technology stores all data in the computer's main memory. This extends the processing capabilities of enterprise resource planning (ERP) systems, enables significant reductions in latency times, and allows to progress requests in parallel (Brocke et al. 2014). Yet, the complex nature of technology and its wide variety of design features complicate the efficient handling of the system. Accordingly, it is not only important whether the technologies are used, but also how they are used (Chapman and Kihn 2009). Effectively implemented and handled technical innovations advance and extend fundamental IS capabilities in MA, providing management accountants with more efficient opportunities. In conclusion, these considerations lead us to expect that the use of innovative technologies is positively associated with IS quality in MA. Thus, we posit the following hypothesis:

H5 Innovative technologies are positively associated with IS quality in MA.

\subsubsection{Data source variety}

Recent technological developments have altered the informational landscape within organizations beyond conventional data types. In particular, IS have shifted from traditional data processing to progressive, automated data capture (Vasarhelyi et al. 2015). This enables organizations to not only process increasing volumes of data but also to exploit new data sources. Prominent examples include real-time market data (Krahel and Titera 2015), e-mail messages, web traffic, video streams (Warren et al. 2015), and social media data (Arnaboldi et al. 2017). The new variety of data sources is accompanied by mainly unstructured data, such as raw textual, audio, and video data, which account for approximately $90 \%$ of total data (Warren et al. 2015). Data volume inflation is often associated with potentially noisy, erroneous, or even missing data (Grover et al. 2018). As a result, management accountants are challenged to integrate data with different quality characteristics into the existing IS infrastructure in MA and to ensure the reliability of the data in order to make new data sources economically usable. Simultaneously, data processing and interpreting become more complex.

The increasing number of data sources bears the risk to exceed current corporate capabilities (Warren et al. 2015) so that mistakes similar to those that occurred during ERP implementation (see e.g., Davenport 1998) will be repeated in the form 


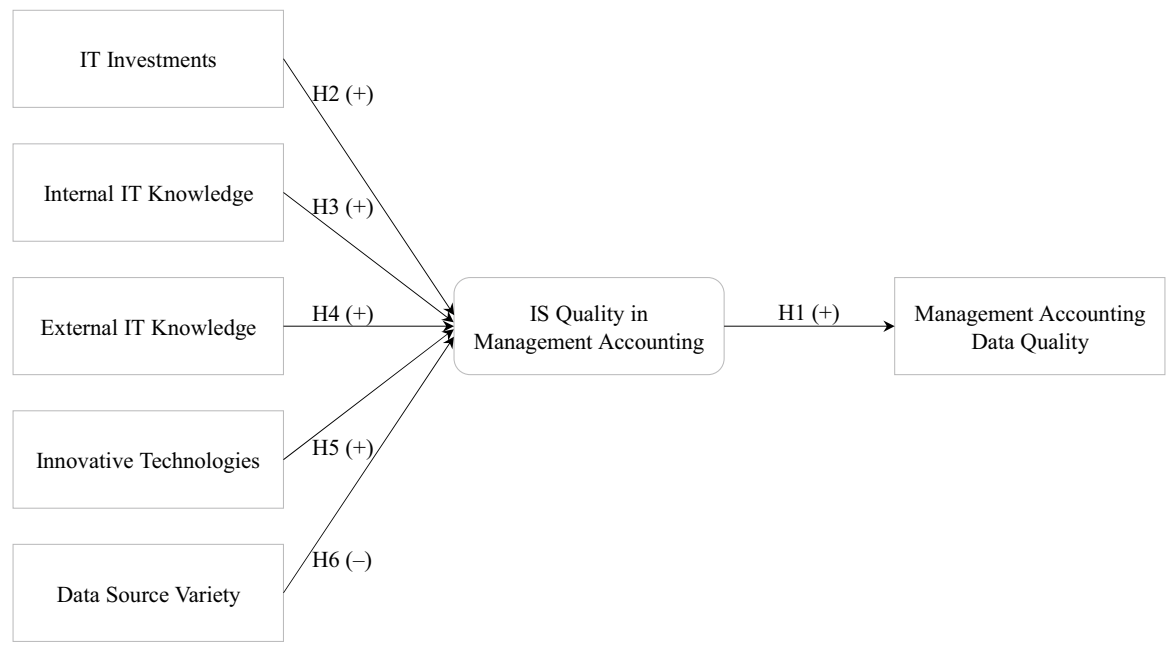

Fig. 1 Research model

of artifact databases and partially integrated data sources, as neither systems nor employees in MA may be sufficiently prepared yet.

Given the increasing complexity and the risk associated with less reliable data in IS, we assume that a variety of data sources have (at least temporarily) a negative impact on IS quality in MA. Thus, we posit the following hypothesis:

H6 Data source variety is negatively associated with IS quality in MA.

Figure 1 graphically summarizes our research model.

\section{Research method}

\subsection{Sample}

To gather data to test our hypotheses, we conducted a survey in November 2017. We randomly selected 1524 German companies from the Dafne database by Bureau van Dijk meeting the following three criteria: (1) the number of employees is at least 100; (2) the annual revenue is at least $€ 30$ million; and (3) the latest account date is 2015,2016 , or 2017. We restricted the sample to medium-sized and large firms because small companies generally show lower application levels of formal MA practices and are less likely to adopt IT (Thong and Yap 1995).

Paper-based questionnaires were sent to the companies along with a cover letter. We asked the respondents to return the survey either by postal mail, e-mail, fax, or online. In total, 174 questionnaires were returned (11.42\%). Our analyses are based on a sample of 143 complete responses, yielding a satisfactory effective response rate of $9.38 \%$. The respondents included management accountants (44), directors of 
MA (81), chief financial officers (CFO) (9), chief executive officers (CEO) (2), and others (6). ${ }^{2}$ The respondents have worked for their current employer for an average of 8.75 years (median $=5.00 ; \mathrm{SD}=8.51$ ). The average working experience of the respondents and the respondents' function within their organization indicate that the respondents have adequate knowledge of their firm's MA practices and the IS employed. In line with this notion, their self-reported IT knowledge is, on average, 4.34 (median $=4.00 ; \mathrm{SD}=0.94$ ) on a scale from one (basic knowledge) to six (high expertise), which indicates that the respondents' IT knowledge is sufficiently good. The sample includes firms operating in a wide range of industries: manufacturing (27), trade/consumer goods (26), automotive industry/suppliers (17), mechanical engineering (16), services (12), chemical/pharmaceutical (9), IT/telecommunications (7), energy supply/waste management (6), construction (5), logistics/transportation (2), and other industries (15). ${ }^{3}$ Of the companies included, $44.06 \%$ have consolidated 2 to 10 firms, whereas $39.86 \%$ consolidated more than 10 firms. Table 1 depicts the characteristics of our sample.

We test for a potential non-response bias in two ways. First, using a $\chi^{2}$ test, we compare the target population and the respondents in terms of company size (e.g., Kihn 2008). The results show no significant difference in size between the target and actual sample at a 5\% significance level. Second, we examine the average ranks for the dependent and independent variables of early and late respondents (Armstrong and Overton 1977) and compare the earliest and latest one-third of respondents according to the return date of the questionnaire. Table 2 presents the results. Late respondents indicated higher levels of external IT knowledge $(p=0.02)$, while all other variables show no significant differences $(p>0.05)$, indicating a low response bias.

\subsection{Variable measurement}

The questionnaire was developed based on previous IS studies (most importantly, Bailey and Pearson 1983; Gable et al. 2008; Gorla et al. 2010; Miller and Doyle 1987). To the extent possible, we use existing, validated scales and refined them if necessary. The nature of our study, however, requires a majority of items to be selfdeveloped for the purpose of this study. We first describe the measurement of the examined variables before validity and reliability are discussed. Most items are rated on six-point Likert scales ranging from one (very low) to six (very high) unless stated otherwise. If reasonable, respondents had the option to check "not specified" if they were unable or unwilling to answer a question.

Management accounting data quality $(M A D Q)$. In the context of MA, data quality refers to the extent to which data meet management accountants' information requirements. Consequently, MADQ is subjective and needs to be assessed within

\footnotetext{
2 Other respondents were the head of IT (2), the interface manager responsible for management accounting/finance/HR/legal and IT (1), the manager for business intelligence/management accounting (1), and the process manager for management accounting (1). One respondent did not answer the question.

3 One respondent indicated "not specified."
} 
Table 1 Characteristics of sample data

\begin{tabular}{|c|c|c|}
\hline Description & Frequency & Percent of sample \\
\hline \multicolumn{3}{|l|}{ Respondent's function } \\
\hline Management accountant & 44 & 30.77 \\
\hline Director of management accounting & 81 & 56.64 \\
\hline $\mathrm{CFO}$ & 9 & 6.29 \\
\hline Managing director/CEO & 2 & 1.40 \\
\hline Other & 6 & 4.20 \\
\hline Not specified & 1 & 0.70 \\
\hline \multicolumn{3}{|l|}{ Tenure } \\
\hline 1 year & 24 & 16.78 \\
\hline Between 1 and 5 years & 50 & 34.97 \\
\hline Between 6 and 10 years & 19 & 13.29 \\
\hline More than 10 years & 49 & 34.27 \\
\hline Not specified & 1 & 0.70 \\
\hline \multicolumn{3}{|l|}{ Number of employees } \\
\hline 250 or less & 19 & 13.29 \\
\hline Between 250 and 500 & 31 & 21.68 \\
\hline Between 500 and 1000 & 22 & 15.38 \\
\hline Between 1000 and 3000 & 36 & 25.17 \\
\hline Between 3000 and 5000 & 10 & 6.99 \\
\hline More than 5000 & 25 & 17.48 \\
\hline \multicolumn{3}{|l|}{ Estimated total annual revenue } \\
\hline Less than $€ 50$ million & 11 & 7.69 \\
\hline Between $€ 50$ and $€ 250$ million & 66 & 46.15 \\
\hline Between $€ 250$ and $€ 500$ million & 18 & 12.59 \\
\hline Between $€ 500$ million and $€ 1$ billion & 20 & 13.99 \\
\hline More than $€ 1$ billion & 28 & 19.58 \\
\hline \multicolumn{3}{|c|}{ Companies consolidated in management accounting } \\
\hline One & 23 & 16.08 \\
\hline Between 2 and 10 & 63 & 44.06 \\
\hline Between 11 and 30 & 30 & 20.98 \\
\hline Between 31 and 100 & 22 & 15.38 \\
\hline More than 100 & 5 & 3.50 \\
\hline
\end{tabular}

The percentages may not add up to $100 \%$ due to rounding 
Table 2 Comparison of early and late respondents

\begin{tabular}{llll}
\hline Variable & $\begin{array}{l}\text { Early respondents } \\
\text { Mean rank }(n=43)\end{array}$ & $\begin{array}{l}\text { Late respondents } \\
\text { Mean rank }(n=39)\end{array}$ & $\begin{array}{l}\text { Wilcoxon-Mann-Whitney } \\
\text { test }\end{array}$ \\
\hline MADQ & 39.80 & 43.37 & $\begin{array}{l}-0.712 \\
(0.476)\end{array}$ \\
& & & -1.295 \\
SYSQUAL & 38.26 & 45.08 & $\begin{array}{l}(0.195) \\
-1.219\end{array}$ \\
ITINVEST & 38.58 & 44.72 & $\begin{array}{l}(0.223) \\
1.646^{*}\end{array}$ \\
& & & $(0.100)$ \\
INTERN_KNOW & 45.47 & 37.13 & $-2.307^{* *}$ \\
& & & $(0.021)$ \\
EXTERN_KNOW & 35.81 & 47.77 & -0.627 \\
& & & $(0.530)$ \\
INNOTECH & 39.98 & 43.18 & -0.183 \\
SOURCE_VAR & 41.09 & 41.95 & $(0.855)$
\end{tabular}

$M A D Q$ management accounting data quality, SYSQUAL IS quality in MA, ITINVEST IT investments, INTERN_KNOW internal IT knowledge, EXTERN_KNOW external IT knowledge, INNOTECH application of innovative technologies, SOURCE_VAR data source variety; See Sect. 3.2 for variable measurement

$* p \leq 0.1 ; * * p \leq 0.05 ; * * * p \leq 0.01$

the specific tasks and context of the individual management accountant (Nelson et al. 2005). To operationalize MADQ we adapt an item from Nelson et al. (2005) and ask respondents to indicate the status quo of overall data quality with regard to IS in MA. ${ }^{4}$

IS quality in MA (SYSQUAL). IS quality in MA is characterized by system flexibility and sophistication, in which sophistication includes ease of use, access and computation time, integration, and automation. To measure ease of use, access and computation time, integration, and flexibility, we adapt items from Bailey and Pearson (1983). Following the advice of Bailey and Pearson (1983, p. 538), we clarified that "the questionnaire is a snapshot of present conditions" by explicitly asking respondents to assess the status quo. The reliability and validity of the items have been thoroughly tested and confirmed in the literature (e.g., Bailey and Pearson 1983; Gable et al. 2008). To capture automation, we use a self-developed item that is consistent with preexisting items. In summary, we address the respondents' perceptions of IS quality by asking them to rate the extent of the actual state of their IS in MA with respect to ease of use (ease), access and computation time (speed), integration (integr), automation (auto), and flexibility/customization (flex).

\footnotetext{
4 The importance of using perceptional measures to assess the success and effectiveness of IS is widely acknowledged in the literature on management information systems (Pierce and O'Dea 2003).
} 
IT investments (ITINVEST). We assess IT investments by asking the respondents to estimate their company's investments in IT relative to their industry to account for industry-specific differences.

Internal IT knowledge (INTERN_KNOW). We ask the respondents to rate the extent to which management accountants have high IT-related knowledge on a scale anchored by one (does not apply) to six (fully applies) to measure internal IT knowledge in MA.

External IT knowledge (EXTERN_KNOW). To measure whether organizations use professional IT consultants to support the MA department, we ask the respondents to indicate whether they employ the services of external IT consultants. The item was assessed on a scale ranging from one (does not apply) to six (fully applies).

Application of innovative technologies (INNOTECH). To assess the number of innovative technologies used within companies, we ask respondents to identify which of the following modern technologies they use in MA: OLAP, cloud computing, in-memory technology, self-service reporting, and mobile device apps for reporting. Thus, INNOTECH reflects the aggregated number of technologies in use.

Data source variety (SOURCE_VAR). Data source variety refers to the number of actively exploited sources in MA. To assess data source variety, we ask the participants to indicate which of the following data sources are used on a regular basis in MA: operative company data, customer relationship management (CRM) data, market research data, social media data, cooperation partner data, clickstream data, text mining, and video/image mining. ${ }^{5}$ The final variable thus comprises the number of identified data sources regularly used in MA.

\subsubsection{Control variables}

We control for potentially confounding effects. First, organizational complexity plays an important role in the adoption of IS (Beard and Sumner 2004). Organizations that are more complex require more effort to implement and operate IS, as more elements have to be considered. Complexity can, therefore, affect IS landscapes in MA and related variables. We use the number of consolidated firms as a proxy for complexity (COMPLEX). ${ }^{6}$ The respondents are asked to indicate the number of firms (i.e., subsidiaries, joint ventures) consolidated in MA within the following categories: 1 consolidated firm, 2-10 consolidated firms, 11-30 consolidated firms, 31-100 consolidated firms, and more than 100 consolidated firms. ${ }^{7}$ Second, following Thong and Yap (1995), firm size may cause differences in the extent of IT adoption because it affects company's IT investments, professional expertise,

\footnotetext{
5 Text mining and video/image mining are not used by the respondents at all and are therefore not included in the variable.

6 The number of consolidated firms is considered a good indicator of complexity as it reflects the complexity of the consolidation process in accounting and of financial analysis. Other potential proxies, such as business units, are usually more aggregated; so we expect the number of consolidated firms to more accurately reflect the complexity for our purpose.

7 We have also coded COMPLEX as a binary variable, i.e., COMPLEX equals one if the company consolidated more firms than the sample median (2-10) and zero otherwise. Repeating the subsequent analysis does not significantly change our results.
} 
Table 3 Instrument validation of IS quality

\begin{tabular}{llllll}
\hline Construct & Indicator & $\begin{array}{l}\text { Standardized factor } \\
\text { loading (CFA/EFA) }\end{array}$ & $\begin{array}{l}\text { Cronbach's } \\
\text { alpha }\end{array}$ & $\begin{array}{l}\text { Composite } \\
\text { reliability }\end{array}$ & $\begin{array}{l}\text { Average } \\
\text { variance } \\
\text { extracted }\end{array}$ \\
\hline SYSQUAL & ease & $0.799 / 0.814$ & 0.765 & 0.847 & 0.529 \\
& speed & $0.659 / 0.741$ & & \\
integr & $0.520 / 0.681$ & & \\
auto & $0.677 / 0.791$ & & \\
& flex & $0.497 / 0.588$ & & \\
\hline
\end{tabular}

$C F A$ confirmatory factor analysis, EFA exploratory factor analysis

complexity, and resistance to change (Raymond 1990; Wilson and Sangster 1992). We control for firm size (SIZE), which we operationalize in terms of annual revenue at the corporate level. ${ }^{8}$ We survey whether the company's revenue is less than $€ 50$ million, between $€ 50$ and $€ 250$ million, between $€ 250$ and $€ 500$ million, between $€ 500$ and $€ 1000$ million, or more than $€ 1000$ million. ${ }^{9}$

\subsection{Validity of survey items and constructs}

To ensure the validity of the survey items, all items were pre-tested by academics with expertise in MA and survey research to minimize bias and maximize the response rate. Further, we examine the reliability and validity of the SYSQUAL construct by performing exploratory and confirmatory factor analyses using robust maximum likelihood (ML) estimation. ${ }^{10}$ We review the factor loadings, Cronbach's alpha, and composite reliability to assess general reliability. As shown in Table 3, all factor loadings are significant and meet the conventional threshold of 0.50 (Hulland 1999; Stevens 2009). Cronbach's alpha (0.76) and composite reliability (0.85) are well above the typical threshold value of 0.70 (Fornell and Larcker 1981), indicating adequate reliability. To estimate convergent validity, we compute the average variance extracted (AVE). The AVE of 0.53 indicates that more than $50 \%$ of the variance is shared between the construct and its indicators (Fornell and Larcker 1981) and implies adequate convergent validity (Chin 1998). The goodness-of-fit statistics of the measurement model from the SEM analysis all meet the recommended values ${ }^{11}\left(\chi_{4}^{2}=1.58\right.$,

\footnotetext{
${ }^{8}$ An alternative proxy for company size based on the number of employees yields similar results.

${ }^{9}$ We have also coded SIZE with two dummy variables; the first indicates whether the firm's revenue is between $€ 250$ and $€ 1000$ million, and the second indicates that the firm's revenue is more than $€ 1000$ million. The omitted variable is for firms with less than $€ 250$ million in revenue. Repeating the subsequent analysis does not change our results significantly. In particular, firms with a revenue of more than $€ 1000$ million show a significant association with data quality, while the variable for smaller firms does not.

${ }^{10}$ Since the measure of IS quality has two underlying dimensions, namely, sophistication and flexibility, the items relating to system sophistication are more highly correlated. Thus, we specify an error covariance with a significant modification index. The results do not vary substantially.

11 The recommended values are at least 0.95 for the CFI, at least 0.90 for the TLI, 0.06 or less for the RMSEA, and 0.08 or less for the SRMR (Hu and Bentler 1999).
} 
$p=0.81$; root mean squared error of approximation (RMSEA) $<0.01$; standardized root mean squared residual $(\mathrm{SRMR})=0.02$; Tucker-Lewis index $(\mathrm{TLI})=1.03$; comparative fit index $(\mathrm{CFI})>0.99)$, thus indicating a good model-data fit.

\section{Empirical results}

\subsection{Descriptive statistics}

Table 4 provides the descriptive statistics for all variables used in the subsequent analysis. MADQ ranges from 2 to 6 , with a mean of $4.38(\mathrm{SD}=1.02)$. Regarding the IS quality dimensions, the respondents rated the current state of access and computation time the highest (mean $=4.08$ ), followed by ease of use $($ mean $=3.72)$, flexibility $($ mean $=3.71)$, automation $($ mean $=3.57)$, and integration (mean=3.12). Overall, the descriptive statistics indicate potential for improvement both for MADQ and for each dimension of IS quality.

Table 4 Descriptive statistics

\begin{tabular}{|c|c|c|c|c|c|}
\hline Item & Mean & Median & SD & Theoretical range & Actual range \\
\hline$M A D Q$ & 4.38 & 5.00 & 1.02 & $1.00-6.00$ & $2.00-6.00$ \\
\hline \multicolumn{6}{|l|}{ SYSQUAL } \\
\hline ease & 3.72 & 4.00 & 1.06 & $1.00-6.00$ & $1.00-6.00$ \\
\hline speed & 4.08 & 4.00 & 1.09 & $1.00-6.00$ & $1.00-6.00$ \\
\hline integr & 3.12 & 3.00 & 1.21 & $1.00-6.00$ & $1.00-6.00$ \\
\hline auto & 3.57 & 4.00 & 1.06 & $1.00-6.00$ & $1.00-6.00$ \\
\hline flex & 3.71 & 4.00 & 1.28 & $1.00-6.00$ & $1.00-6.00$ \\
\hline ITINVEST & 3.82 & 4.00 & 1.16 & $1.00-6.00$ & $1.00-6.00$ \\
\hline INTERN_KNOW & 4.36 & 4.00 & 1.03 & $1.00-6.00$ & $2.00-6.00$ \\
\hline EXTERN_KNOW & 3.09 & 3.00 & 1.64 & $1.00-6.00$ & $1.00-6.00$ \\
\hline \multicolumn{6}{|l|}{ INNOTECH } \\
\hline$O L A P$ & 0.50 & 0.00 & 0.50 & $0.00-1.00$ & $0.00-1.00$ \\
\hline cloud computing & 0.12 & 0.00 & 0.33 & $0.00-1.00$ & $0.00-1.00$ \\
\hline in-memory & 0.15 & 0.00 & 0.36 & $0.00-1.00$ & $0.00-1.00$ \\
\hline self-service reporting & 0.72 & 1.00 & 0.45 & $0.00-1.00$ & $0.00-1.00$ \\
\hline mobile reporting & 0.09 & 0.00 & 0.29 & $0.00-1.00$ & $0.00-1.00$ \\
\hline \multicolumn{6}{|l|}{ SOURCE_VAR } \\
\hline operative data & 1.00 & 1.00 & 0.00 & $0.00-1.00$ & $1.00-1.00$ \\
\hline$C R M$ data & 0.33 & 0.00 & 0.47 & $0.00-1.00$ & $0.00-1.00$ \\
\hline market research data & 0.16 & 0.00 & 0.37 & $0.00-1.00$ & $0.00-1.00$ \\
\hline social media data & 0.02 & 0.00 & 0.14 & $0.00-1.00$ & $0.00-1.00$ \\
\hline cooperation partner data & 0.11 & 0.00 & 0.31 & $0.00-1.00$ & $0.00-1.00$ \\
\hline clickstream data & 0.02 & 0.00 & 0.14 & $0.00-1.00$ & $0.00-1.00$ \\
\hline COMPLEX & 2.46 & 2.00 & 1.05 & $1.00-5.00$ & $1.00-5.00$ \\
\hline SIZE & 2.92 & 2.00 & 1.30 & $1.00-5.00$ & $1.00-5.00$ \\
\hline
\end{tabular}


Table 5 Correlation matrix

(1) (2)

(3)

(4)

(5)

(6)

(7)

(8)

(9)

\begin{tabular}{|c|c|c|c|c|c|c|c|c|}
\hline (1) $M A D Q$ & 1.000 & & & & & & & \\
\hline (2) $S Y S Q U A L$ & $0.361 * * *$ & 1.000 & & & & & & \\
\hline (3) ITINVEST & $0.195 * *$ & $0.590 * * *$ & 1.000 & & & & & \\
\hline (4) INTERN_KNOW & 0.093 & $0.401 * * *$ & 0.062 & 1.000 & & & & \\
\hline (5) $E X T E R N \_K N O W$ & $V 0.267 * * *$ & $0.519 * * *$ & 0.112 & -0.034 & 1.000 & & & \\
\hline (6) INNOTECH & $0.269 * * *$ & $0.561 * * *$ & $0.250 * * *$ & $=0.059$ & $0.206 * *$ & 1.000 & & \\
\hline (7) $S O U R C E \_V A R$ & -0.012 & $-0.143 *$ & 0.074 & 0.006 & $0.237 * * *$ & 0.130 & 1.000 & \\
\hline (8) COMPLEX & 0.091 & $0.307 * * *$ & 0.139* & -0.046 & $0.173 * *$ & $0.264 * * *$ & 0.063 & 1.000 \\
\hline SIZE & $0.258 * * *$ & $=0.243 * * *$ & 0.103 & -0.055 & $0.168 * *$ & $0.342 * * *$ & 0.1171 & $0.475 * * *$ \\
\hline
\end{tabular}

This table presents the Spearman correlation coefficients

${ }^{*} p \leq 0.1 ; * * p \leq 0.05 ; * * * p \leq 0.01$

The company's willingness to invest in IT in comparison to its industry (mean=3.82) and internal IT knowledge in MA (mean=4.36) are slightly above average. The mean value of external IT knowledge $($ mean $=3.09)$ points to moderate use of consultants, although the tendency of organizations to employ the services of consultants varies widely $(\mathrm{SD}=1.64)$. Regarding technologies, $72.34 \%$ of firms use self-service reporting in MA, 49.64\% have implemented OLAP, while in-memory technology (15.44\%), cloud computing (12.14\%), and mobile device apps (9.09\%) are used to a lesser extent. In summary, the usage rates indicate that many technological advances have not yet been applied on a wide scale in MA and that the opportunities of various data sources have not yet been fully exploited. Regarding the different sources of data, all surveyed organizations use operational company data in MA, while other data sources are used rather irregularly.

Table 5 presents the Spearman correlation coefficients. SYSQUAL is positively correlated with $M A D Q(p<0.01)$. ITINVEST, INTERN_KNOW, EXTERN_ $K N O W$, and INNOTECH are positively correlated with SYSQUAL (all $p<0.01$ ), while SOURCE_VAR is negatively correlated with SYSQUAL $(p<0.10)$. The correlations provide initial support for our predictions. Further, although some correlations are above 0.50 , all variance inflation factors are below 2.00 , indicating that multicollinearity is unlikely to affect our inferences.

\subsection{Hypothesis tests}

We examine our hypotheses using an SEM with maximum likelihood estimation and robust standard errors, as shown in Table $6 .{ }^{12}$ Model 1 (columns 1 and 2) presents the associations of IS quality and its determinants. Model 2 (columns 3 and 4) includes the control variables for complexity and firm size. In both models, we also control for the direct effects of each independent variable on MADQ.

As the results of models 1 and 2 do not differ significantly, we discuss the full model (Model 2) in the following. Regarding the goodness-of-fit statistics,

\footnotetext{
12 We include robust standard errors to correct for heteroscedasticity, as indicated by the Breusch-Pagan test $\left(\chi^{2}=104.48, p=0.00\right)$.
} 
Table 6 Results of the structural model

\begin{tabular}{|c|c|c|c|c|}
\hline & \multicolumn{2}{|c|}{ Model 1: Main effects } & \multicolumn{2}{|c|}{ Model 2: Control variables included } \\
\hline & SYSQUAL & $M A D Q$ & SYSQUAL & $M A D Q$ \\
\hline SYSQUAL & - & $\begin{array}{l}\mathbf{0 . 3 3 3}^{* * *} \\
(\mathbf{0 . 0 0 1 )}\end{array}$ & - & $\begin{array}{l}\mathbf{0 . 3 3 4}^{* * * *} \\
(\mathbf{0 . 0 0 1 )}\end{array}$ \\
\hline ITINVEST & $\begin{array}{l}0.209^{* *} \\
(0.022)\end{array}$ & $\begin{array}{l}0.050 \\
(0.507)\end{array}$ & $\begin{array}{l}\mathbf{0 . 2 0 3}^{* *} \\
(\mathbf{0 . 0 2 5})\end{array}$ & $\begin{array}{l}0.060 \\
(0.400)\end{array}$ \\
\hline INTERN_KNOW & $\begin{array}{l}0.208^{* *} \\
(0.015)\end{array}$ & $\begin{array}{l}-0.030 \\
(0.712)\end{array}$ & $\begin{array}{l}0.211^{* * *} \\
(0.013)\end{array}$ & $\begin{array}{l}-0.020 \\
(0.806)\end{array}$ \\
\hline EXTERN_KNOW & $\begin{array}{l}0.252^{* * * *} \\
(0.003)\end{array}$ & $\begin{array}{l}\mathbf{0 . 1 4 3}^{*} \\
(\mathbf{0 . 0 7 6 )}\end{array}$ & $\begin{array}{l}0.247^{* * *} \\
(0.005)\end{array}$ & $\begin{array}{l}0.140^{*} \\
(0.075)\end{array}$ \\
\hline INNOTECH & $\begin{array}{l}0.191^{* *} \\
(0.041)\end{array}$ & $\begin{array}{l}0.147 \\
(0.113)\end{array}$ & $\begin{array}{l}\mathbf{0 . 1 8 0}{ }^{* *} \\
(0.047)\end{array}$ & $\begin{array}{l}0.099 \\
(0.320)\end{array}$ \\
\hline SOURCE_VAR & $\begin{array}{l}-0.184^{* * * *} \\
(0.010)\end{array}$ & $\begin{array}{l}-0.042 \\
(0.553)\end{array}$ & $\begin{array}{l}-0.181^{* * * *} \\
(\mathbf{0 . 0 1 0})\end{array}$ & $\begin{array}{l}-0.068 \\
(0.308)\end{array}$ \\
\hline COMPLEX & & & $\begin{array}{l}0.051 \\
(0.616)\end{array}$ & $\begin{array}{l}-0.127 \\
(0.205)\end{array}$ \\
\hline SIZE & & & $\begin{array}{l}-0.005 \\
(0.963)\end{array}$ & $\begin{array}{l}0.250^{* * * *} \\
(0.006)\end{array}$ \\
\hline$R^{2}$ & 0.243 & 0.228 & 0.245 & 0.272 \\
\hline
\end{tabular}

This table presents the results of the structural equation model. The values presented for models 1 and 2 indicate standardized coefficient estimates, while $p$ values are reported in parentheses

Goodness-of-fit statistics for model 1 (model 2): Degrees of freedom $(d f)=28(36), \chi^{2}=31.272(38.672)$, $p=0.305$ (0.350), RMSEA =0.029 (0.023), SRMR =0.048 (0.045), TLI=0.978 (0.983), CFI $=0.986$ (0.989)

RMSEA root mean squared error of approximation, SRMR standardized root mean squared residual, TLI Tucker Lewis Index, CFI comparative fit index. The measurement model estimates are based on ML estimation

$* p \leq 0.1 ; * * p \leq 0.05 ; * * * p \leq 0.01$

our model's $\chi^{2}$ is not significantly different from the saturated model $\left(\chi_{28}^{2}=38.67\right.$, $p=0.35$ ). The other goodness-of-fit indices indicate an adequate model fit $(\mathrm{CFI}=0.99$; TLI $=0.98$; $\mathrm{RMSEA}=0.02$; $\mathrm{SRMR}<0.05)$. The $R^{2}$ for IS quality is 0.245 and 0.272 for MADQ, indicating that the model presented can explain a relevant portion of the variance in the endogenous variables.

Hypothesis $\mathrm{H} 1$ investigates the relationship between IS quality in MA and MADQ. The results show that SYSQUAL is positively associated with $M A D Q$ $(\beta=0.33, p<0.01)$, which is in line with our prediction. Thus, H1 is supported. Accordingly, the results indicate that firms emphasizing IS quality in MA are more likely to be rewarded with higher data quality in MA. 
The next set of hypotheses examines the potential drivers of IS quality. $\mathrm{H} 2$ predicts that IT investments are positively associated with IS quality in MA. In line with $\mathrm{H} 2$, the path between ITINVEST and SYSQUAL is positive and significant $(\beta=0.20, p=0.03)$. According to $\mathrm{H} 3$, internal IT knowledge is positively associated with IS quality in MA. The results show a significant association between INTERN_KNOW and SYSQUAL $(\beta=0.21, p=0.01)$, supporting H3. Regarding H4, we expect that higher levels of external knowledge increase IS quality in MA. The results support the prediction as EXTERN_KNOW is positively associated with SYSQUAL $(\beta=0.25, p<0.01)$. Additionally, the direct association of EXTERN_KNOW and $M A D Q$ is marginally significant and positive $(\beta=0.14$, $p=0.08$ ), indicating that external knowledge also directly benefits MADQ. Further, as predicted in $\mathrm{H} 5$, the application of innovative technologies (INNOTECH) is positively associated with SYSQUAL $(\beta=0.18, p=0.05)$. Finally, H6 hypothesizes that data source variety is negatively associated with IS quality in MA. The SEM results reveal that the association between SOURCE_VAR and SYSQUAL is negative and statistically significant $(\beta=-0.18, p=0.01)$, which provides support for H6. With respect to the control variables, we find that SIZE is positively associated with $M A D Q(\beta=0.25, p<0.01)$.

Figure 2 graphically illustrates the results of the full SEM. Overall, our results support our hypotheses and suggest that higher levels of IS quality in MA increase MADQ (H1), and that IS quality in MA is directly affected by the independent variables as predicted in H2-H6. Additionally, external IT knowledge is found to directly affect MADQ. The positive association between IS quality in MA and MADQ further suggests that the determinants of IS quality in MA may indirectly affect MADQ by increasing IS quality.

Using the Sobel (1987) test, we formally test whether the effects of our independent variables on MADQ are mediated by IS quality in MA. To overcome

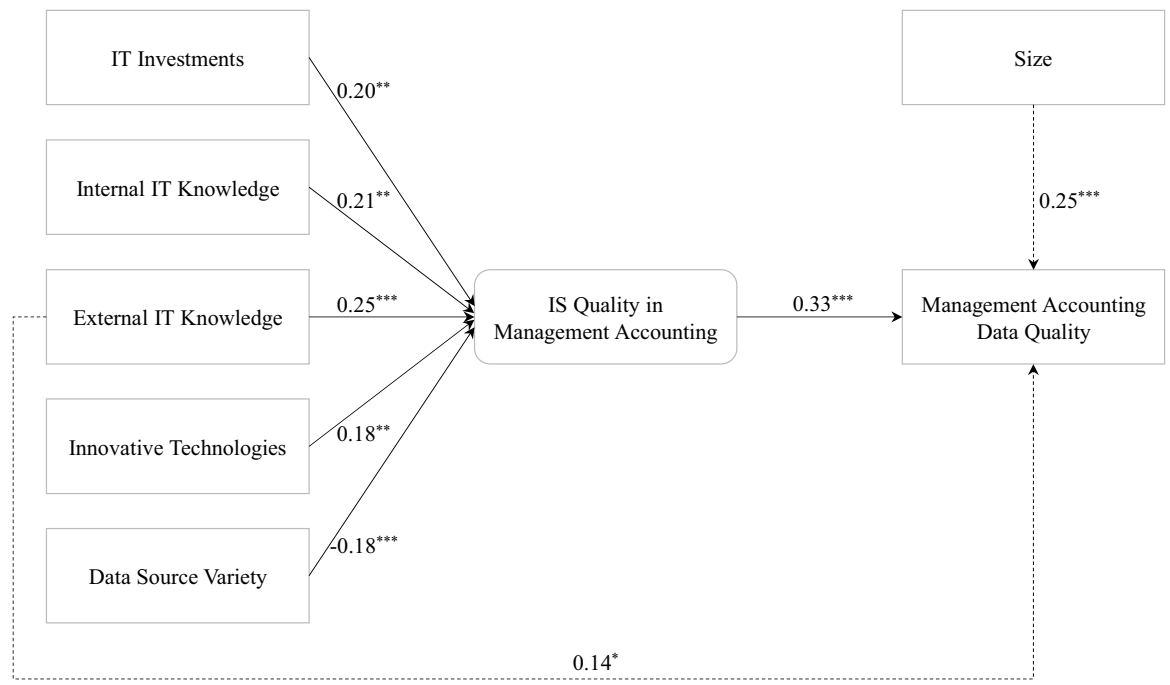

Fig. 2 Structural equation model 
Table 7 Sobel tests of indirect effects and percentile bootstrap confidence interval

\begin{tabular}{lllllrr}
\hline Indirect effect & Value & SE & $Z$ & $p$ & \multicolumn{2}{l}{$\begin{array}{l}\text { 95\% confidence interval } \\
\text { limits }\end{array}$} \\
\cline { 5 - 7 } & & & & & Lower & Upper \\
\hline ITINVEST & 0.068 & 0.034 & 1.78 & 0.076 & 0.003 & 0.147 \\
INTERN_KNOW & 0.071 & 0.033 & 2.14 & 0.032 & 0.009 & 0.153 \\
EXTERN_KNOW & 0.082 & 0.025 & 2.02 & 0.043 & 0.007 & 0.116 \\
INNOTECH & 0.060 & 0.031 & 1.71 & 0.088 & 0.002 & 0.139 \\
SOURCE_VAR & -0.060 & 0.032 & -2.11 & 0.035 & -0.146 & -0.005 \\
\hline
\end{tabular}

This table presents the results of Sobel tests and percentile bootstrap confidence intervals based on 5000 bootstrap samples

$S E$ standard error

the potential shortcomings of the Sobel test related to the restrictive distribution assumption, we follow the procedure of Preacher and Hayes $(2004,2008)$ and additionally apply bootstrapping to calculate percentile confidence intervals. ${ }^{13}$ Table 7 reports the examined indirect effects and the corresponding 95\% confidence intervals of the mediation analyses.

To determine the mediation type, we examine the total, indirect, and direct effects of each independent variable (Mathieu and Taylor 2006). The total effects (untabulated) of INTERN_KNOW $(\beta=0.05, p=0.55)$ and INNOTECH $(\beta=0.16$, $p=0.12$ ) suggest the absence of a significant zero-order effect on $M A D Q$ for both variables. Additionally, as shown in Table 7, the indirect effects of INTERN_KNOW $(\beta=0.07, p=0.03)$ and INNOTECH $(\beta=0.06, p=0.09)$ are (marginally) significant, while the direct effects on $M A D Q$ are not (INTERN_KNOW: $\beta=-0.02, p=0.81$; INNOTECH: $\beta=0.10, p=0.32$, see Table 6). These results hint to a pattern of an indirect-only mediation (Zhao et al. 2010). The bootstrapped confidence intervals of the indirect effects do not contain zero, thus supporting the indirect effects at a $5 \%$ significance level. Although INTERN_KNOW shows a significantly positive indirect effect, the direct effect of INTERN_KNOW is negative, thus establishing an inconsistent mediation (MacKinnon et al. 2007).

ITINVEST $(\beta=0.13, p=0.08)$ and SOURCE_VAR $(\beta=-0.13, p=0.05)$ show significant total effects. In addition, both variables exhibit significant indirect effects (ITINVEST: $\beta=0.07, p=0.08$; SOURCE_VAR: $\beta=-0.06, p=0.04$ ), while the direct effects are insignificant (ITINVEST: $\beta=0.06, p=0.40$; SOURCE_VAR: $\beta=-0.07$, $p=0.31$ ). The confidence intervals of the indirect effects do not contain zero, supporting the indirect effects. Accordingly, both variables fulfill the conditions of full mediation.

\footnotetext{
13 Specifically, the Sobel test assumes a normal sampling distribution of indirect effects even though the actual distribution is usually skewed (Preacher and Hayes 2004). Bootstrapping generates an empirical sampling distribution resulting in more valid and powerful interference for tests of indirect effects.
} 
Finally, the association of EXTERN_KNOW on MADQ through SYSQUAL implies partial mediation, as the total effect $(\beta=0.22, p<0.01)$, indirect effect $(\beta=0.08, p=0.04)$, and direct effect $(\beta=0.14, p=0.08)$ are significant and the confidence interval for the mediation path does not include zero.

In summary, the analysis indicates that all variables are mediated by IS quality in MA and thus affect MADQ indirectly but not directly, except for external IT knowledge. Thus, IT investments, internal IT knowledge, external IT knowledge, and the application of innovative technologies appear to be beneficial for MADQ by inducing higher levels of IS quality in MA, whereas data source variety harms MADQ by decreasing IS quality. Additionally, external IT knowledge shows the potential to increase MADQ directly. Both control variables do not exhibit significant indirect effects (COMPLEX: $\beta=0.02, p=0.61$; SIZE: $\beta<0.01, p=0.96$; untabulated).

\section{Discussion and conclusion}

Motivated by the importance of data quality for management accountants, this study focuses on the dependence of data quality on IS quality in MA. By empirically investigating how MADQ depends on IS quality and what determinants may drive IS quality in MA, this study contributes to the growing research on IS. In doing so, we transfer insights of comprehensive IS in organizations (e.g., Gable et al. 2008; Gorla et al. 2010; Nelson et al. 2005) to an MA setting. Thus far, research on IS in the MA environment has produced only a limited number of empirical studies (Granlund 2011), mostly case studies (e.g., Dechow and Mouritsen 2005; Quattrone and Hopper 2006; Scapens and Jazayeri 2003). The existing literature has predominantly focused on subsystems of IS, such as ERP systems (Rom and Rohde 2007). The present study further advances empirical analysis of IS and MA by drawing on survey data from 143 medium-sized and large German companies.

The analysis of the SEM provides support for our hypotheses. First, our study finds evidence that higher levels of IS quality in MA result in higher MADQ. This finding is of particular interest because it implies that upgrading systems will result in increased MADQ. Second, the findings show that IT investments, internal IT knowledge, external IT knowledge, and the application of innovative technologies exhibit the potential to enhance IS quality in MA. With respect to the use of different data sources, our model suggests that an increase in data source variety reduces IS quality. This finding can be attributed to the increasing complexity of integrating and processing new data sources, which may currently overwhelm the capacities of organizations. The difficulty in dealing with different data sources may be related to differences in the quality of data. For example, while traditionally used data sources, especially financial data, mainly represent structured, reliable data, new data sources, such as social media, provide unstructured, less reliable data that are difficult to prepare and to process. Finally, we conclude that IS quality in MA mediates the relationship between the investigated determinants of IS quality in MA and MADQ. More precisely, IT investments, internal and external IT knowledge, the application of innovative technologies, and data source variety indirectly affect MADQ through IS 
quality in MA. Contrary to the actual intention of achieving better data quality by integrating new data sources, it appears that data source variety indirectly harms MADQ by deteriorating IS quality. This finding is consistent with the argument that insufficiently integrated data sources might contribute to a "data overload" (Krahel and Titera 2015). Currently, it appears that the disadvantages of new data sources exceed the intended positive effects of drawing on a more comprehensive database.

The results of the study have several implications for the literature and management accountants' practice. While widely neglected by prior research, we consider automation to be particularly relevant in MA. Routine tasks, such as bookkeeping or invoicing, can be easily automated, enabling management accountants to focus more on cognitively complex tasks (Scapens and Jazayeri 2003; Wilson and Sangster 1992). Thus, we propose to incorporate automation as an indicator of IS quality. Further, by establishing the link between IS quality in MA and MADQ, the study suggests that companies are well-advised to concentrate on IS quality. Yet, a remarkable number of firms operate outdated IS in MA, suggesting substantial deficiencies. In this regard, the identified determinants of IS quality in MA provide concrete guidance for practice to improve IS quality and, in turn, MADQ. As such, our study contributes to research on the resource-based view of IS (Bharadwaj 2000; Wade and Hulland 2004). In particular, the results underline that IT investments are beneficial for improving IS quality. A finding, which is of special interest, given that organizations face a high uncertainty whether potential investments will pay off and are thus often reluctant to invest in IS. Further, by indicating the importance of IT knowledge, our study contributes to the question what skills are necessary for today's management accountants. Through the provision of IT training and the selection of skilled candidates, organizations may complement existing professional expertise in their MA departments with required IT skills. Organizations may also benefit from the expertise of external consultants. Furthermore, the low usage rates of innovative technologies in MA hint to unrealized potential that companies may want to exploit. To appropriately select suitable technologies, organizations are required to monitor and test emerging developments constantly. Finally, we voice concerns that the larger volumes of data resulting from additional sources with different quality characteristics may not necessarily lead to higher data quality for unprepared users. Practitioners should therefore exercise caution when handling information arising from new data sources. It seems sensible to prioritize data harmonization before endeavoring to gather as much data as possible.

To overcome the negative effects of data source variety, future research can examine the specific characteristics of the data sources with regard to their potential use in MA and the handling of unstructured data while ensuring reliability. Moreover, research and practice should continue to uncover ways to increase IS quality, and thus MADQ.

Our findings are subject to several limitations, which provide avenues for future research. First, due to the survey approach, we cannot rule out the possibility that respondents' answers are potentially biased, although we constructed the questionnaire with the utmost care based on prior research. Moreover, the study captures employees' perceptions that may not accurately represent actual practice in MA. 
Nevertheless, using perceptual measures is inevitable and reasonable because it is ultimately the user who operates the system. Second, while the IT landscape is continuously changing, we stress that our study represents only one point in time and concentrates on a selected number of technologies and data sources. New technologies emerge, IS shift, and in turn, the role of management accountants changes. This points to an opportunity for future research to analyze IS developments in MA and to build on this study. Further, while our study focuses on the extent of technologies in use, future research can also incorporate how the technologies are actually used. Third, our survey was administered in Germany, resulting in a sample of 143 medium-sized and large organizations, which may limit the generalizability of the results. Future research may reassess the findings in other countries and/or in different constellations.

Acknowledgements Open Access funding provided by Projekt DEAL.

Open Access This article is licensed under a Creative Commons Attribution 4.0 International License, which permits use, sharing, adaptation, distribution and reproduction in any medium or format, as long as you give appropriate credit to the original author(s) and the source, provide a link to the Creative Commons licence, and indicate if changes were made. The images or other third party material in this article are included in the article's Creative Commons licence, unless indicated otherwise in a credit line to the material. If material is not included in the article's Creative Commons licence and your intended use is not permitted by statutory regulation or exceeds the permitted use, you will need to obtain permission directly from the copyright holder. To view a copy of this licence, visit http://creativecommons.org/licen ses/by/4.0/.

\section{References}

Armstrong, J. S., \& Overton, T. S. (1977). Estimating nonresponse bias in mail surveys. Journal of Marketing Research, 14(3), 396-402.

Arnaboldi, M., Busco, C., \& Cuganesan, S. (2017). Accounting, accountability, social media and big data: Revolution or hype? Accounting, Auditing \& Accountability Journal, 30(4), 762-776.

Au, N., Ngai, E. W. T., \& Cheng, T. C. E. (2002). A critical review of end-user information system satisfaction research and a new research framework. Omega - The International Journal of Management Science, 30(6), 451-478.

Bailey, J. E., \& Pearson, S. W. (1983). Development of a tool for measuring and analyzing computer user satisfaction. Management Science, 29(5), 530-545.

Balkan, S., \& Goul, M. (2010). Advances in predictive modeling: How in-database analytics will evolve to change the game. Business Intelligence Journal, 15(2), 17-25.

Beard, J. W., \& Sumner, M. (2004). Seeking strategic advantage in the post-net era: Viewing ERP systems from the resource-based perspective. Journal of Strategic Information Systems, 13(2), 129-150.

Bharadwaj, A. S. (2000). A resource-based perspective on information technology capability and firm performance: An empirical investigation. MIS Quarterly, 24(1), 169-196.

Bhimani, A., \& Willocks, L. (2014). Digitisation, 'Big Data' and the transformation of accounting information. Accounting and Business Research, 44(4), 469-490.

Booth, P., Matolcsy, Z., \& Wieder, B. (2000). The impacts of enterprise resource planning systems on accounting practice-The Australian experience. Australian Accounting Review, 10(22), 4-18.

Bravo, E. R., Santana, M., \& Rodon, J. (2016). Automating and informating: Roles to examine technology's impact on performance. Behavior \& Information Technology, 35(7), 586-604.

Brocke, J., Debortoli, S., Müller, O., \& Reuter, N. (2014). How in-memory technology can create business value: Insights from the Hilti Case. Communications of the Association for Information Systems, 34(1), 151-167. 
Burns, J., \& Scapens, R. W. (2000). Conceptualizing management accounting change: An institutional framework. Management Accounting Research, 11(1), 3-25.

Caglio, A. (2003). Enterprise resource planning systems and accountants: Towards hybridization? European Accounting Review, 12(1), 123-153.

Chapman, C. S., \& Kihn, L.-A. (2009). Information system integration, enabling control and performance. Accounting, Organizations and Society, 34(2), 151-169.

Chen, H., Chiang, R. H. L., \& Storey, V. C. (2012). Business intelligence and analytics: From big data to big impact. MIS Quarterly, 36(4), 1165-1188.

Chin, W. W. (1998). Issues and opinion on structural equation modeling. MIS Quarterly, 22(1), 7-16.

Davenport, D. H. (1998). Putting the enterprise into the enterprise system. Harvard Business Review, 76(4), 121-131.

Davis, F. D. (1989). Perceived usefulness, perceived ease of use, and user acceptance of information technology. MIS Quarterly, 13(3), 319-340.

Davis, F. D., Bagozzi, R. P., \& Warshaw, P. R. (1989). User acceptance of computer technology. A comparison of two theoretical models. Management Science, 35(8), 982-1003.

Dechow, N., \& Mouritsen, J. (2005). Enterprise resource planning systems, management control and the quest for integration. Accounting, Organizations and Society, 30(7-8), 691-733.

DeLone, W. H., \& McLean, E. R. (1992). Information systems success: The quest for the dependent variable. Information Systems Research, 3(1), 60-95.

DeLone, W. H., \& McLean, E. R. (2003). The DeLone and McLean model of information system success: A ten-year update. Journal of Management Information Systems, 19(4), 9-30.

Duncan, N. B. (1995). Capturing flexibility of information technology infrastructure: A study of resource characteristics and their measure. Journal of Management Information Systems, 12(2), 37-57.

Fornell, C., \& Larcker, D. F. (1981). Evaluating structural equation models with unobservable variables and measurement error. Journal of Marketing Research, 18(1), 39-50.

Fox, C., Levitin, A., \& Redman, T. (1994). The notion of data and its quality dimensions. Information Processing and Management, 30(1), 9-19.

Gable, G. G. (1991). Consultant engagement for computer system selection: A pro-active client role in small enterprises. Information \& Management, 20(2), 83-93.

Gable, G. G., Sedera, D., \& Chan, T. (2008). Re-conceptualizing information system success: The ISimpact measurement model. Journal of the Association for Information Systems, 9(7), 377-408.

Gatian, A. W. (1994). Is user satisfaction a valid measure of system effectiveness? Information \& Management, 26(3), 119-131.

Gattiker, T. F., \& Goodhue, D. L. (2004). Understanding the local-level costs and benefits of ERP through organizational information processing theory. Information \& Management, 41(4), 431-443.

Gorla, N., Somers, T. M., \& Wong, B. (2010). Organizational impact of system quality, information quality, and service quality. Journal of Strategic Information Systems, 19(3), 207-228.

Granlund, M. (2011). Extending AIS research to management accounting and control issues: A research note. International Journal of Accounting Information Systems, 12(1), 3-19.

Grover, V., Chiang, R. H. L., Liang, T. L., \& Zhang, D. (2018). Creating strategic business value from big date analytics: A research framework. Journal of Management Information Systems, 25(2), $388-423$.

Häkkinen, L., \& Hilmola, O. (2008). Life after ERP implementation: Long-term development of user perceptions of system success in an after-sales environment. Journal of Enterprise Information Management, 21(3), 285-310.

Hashem, I. A. T., Yaqoob, I., Anuar, N. B., Mokhatar, S., Gani, A., \& Khan, S. U. (2015). The rise of "big data" on cloud computing: Review and open research issues. Information Systems, 47, 98-115.

Hu, L., \& Bentler, P. M. (1999). Cutoff criteria for fit indexes in covariance structure analysis: Conventional criteria versus new alternatives. Structural Equation Modeling: A Multidisciplinary Journal, $6(1), 1-55$.

Huikku, J., Hyvönen, T., \& Järvinen, J. (2017). The role of predictive analytics project initiator in integration of financial and operational forecasts. Baltic Journal of Management, 12(4), 427-446.

Hulland, J. (1999). Use of partial least squares (PLS) in strategic management research: A review of four recent studies. Strategic Management Journal, 20(2), 195-204.

Hyvönen, J. (2007). Strategy, performance measurement techniques and information technology of the firm and their links to organizational performance. Management Accounting Research, 18(3), 343-366. 
Igbaria, M., Guimaraes, T., \& Davis, G. B. (1995). Testing the determinants of microcomputer usage via a structural equation model. Journal of Management Information Systems, 11(4), 87-114.

Igbaria, M., Zinatelli, N., Cragg, P., \& Cavaye, A. L. M. (1997). Personal computing acceptance factors in small firms: A structural equation model. MIS Quarterly, 21(3), 279-305.

Kihn, L. A. (2008). The determinants of multiple forms of controls in foreign subsidiary manager evaluations. International Journal of Accounting, Auditing and Performance Evaluation, 5(2), 157-182.

Kivijärvi, H., \& Saarinen, T. (1995). Investment in information systems and the financial performance of the firm. Information \& Management, 28(2), 143-163.

Kole, M. A. (1983). Going outside for MIS implementation. Information \& Management, 6(5), 261-268.

Krahel, J. P., \& Titera, W. R. (2015). Consequences of big data and formalization on accounting and auditing standards. Accounting Horizons, 29(2), 409-422.

Laudon, J. P., \& Laudon, K. C. (2020). Management information systems: Managing the digital firm. London: Pearson Education.

MacKinnon, D. P., Fairchild, A. J., \& Fritz, M. S. (2007). Mediation analysis. Annual Review of Psychology, 58, 593-614.

Mahmood, M. A., \& Mann, G. J. (2000). Special issue: Impacts of information technology investment on organizational performance. Journal of Management Information Systems, 17(1), 3-10.

Mathieu, J. E., \& Taylor, S. R. (2006). Clarifying conditions and decision points for mediational type inferences in organizational behavior. Journal of Organizational Behavior, 27(8), 1031-1056.

Miller, J., \& Doyle, B. A. (1987). Measuring the effectiveness of computer-based information systems in the financial services sector. MIS Quarterly, 11(1), 107-124.

Neidleman, L. D. (1979). Computer usage by small and medium sized European firms: An empirical study. Information \& Management, 2(2), 67-77.

Nelson, R. R., \& Cheney, P. H. (1987). Training end users: An exploratory study. MIS Quarterly, 11(4), 547-559.

Nelson, R. R., Todd, P. A., \& Wixom, B. H. (2005). Antecedents of information and system quality: An empirical examination within the context of data warehousing. Journal of Management Information Systems, 21(4), 199-235.

Parasuraman, R., \& Riley, V. (1997). Human factors: Humans and automation: Use, misuse, disuse, abuse. The Journal of the Human Factors and Ergonomics Society, 39(2), 230-253.

Peppard, J., Lambert, R., \& Edwards, C. (2000). Whose job is it anyway?: Organizational information competencies for value creation. Information Systems Journal, 10(4), 291-322.

Peppard, J., \& Ward, J. (2004). Beyond strategic information systems: Towards an IS capability. Journal of Strategic Information Systems, 13(2), 167-194.

Peters, M. D., Wieder, B., Sutton, S. G., \& Wakefield, J. (2016). Business intelligence systems use in performance measurement capabilities: Implications for enhanced competitive advantage. International Journal of Accounting Information Systems, 21, 1-17.

Pierce, B., \& O'Dea, T. (2003). Management accounting information and the needs of managers: Perceptions of managers and accountants compared. The British Accounting Review, 35(3), 257-290.

Prasad, A., \& Green, P. (2015). Organizational competencies and dynamic accounting information system capability: Impact on AIS processes and firm performance. Journal of Information Systems, 29(3), 123-149.

Preacher, K. J., \& Hayes, A. F. (2004). SPSS and SAS procedures for estimating indirect effects in simple mediation models. Behavior Research Methods, Instruments \& Computers, 36(4), 717-731.

Preacher, K. J., \& Hayes, A. F. (2008). Asymptotic and resampling strategies for assessing and comparing indirect effects in multiple mediator models. Behavior Research Methods, 40(3), 879-891.

Quattrone, P. (2016). Management accounting goes digital: Will the move make it wiser? Management Accounting Research, 31(2), 118-122.

Quattrone, P., \& Hopper, T. (2006). What is IT? SAP, accounting, and visibility in a multinational organization. Information and Organization, 16(3), 212-250.

Ragowsky, A., Licker, P. S., \& Gefen, D. (2012). Organizational IT maturity (OITM): A measure of organizational readiness and effectiveness to obtain value from its information technology. Information Systems Management, 29(2), 148-160.

Rao, Y., Guo, K. H., \& Chen, Y. (2015). Information systems maturity, knowledge sharing and firm performance. International Journal of Accounting \& Information Management, 23(2), 106-127.

Raymond, L. (1990). Organizational context and information system success: A contingency approach. Journal of Management Information Systems, 6(4), 5-20. 
Richins, G., Stapleton, A., Stratopoulos, T. C., \& Wong, C. (2017). Big data analytics: Opportunity or threat for the accounting profession? Journal of Information Systems, 31(3), 63-79.

Rom, A., \& Rohde, C. (2007). Management accounting and integrated information systems: A literature review. International Journal of Accounting Information Systems, 8(1), 40-68.

Saraf, N., Langdon, C. S., \& Gosain, S. (2007). IS application capabilities and relational value in interfirm partnerships. Information Systems Research, 18(3), 320-339.

Scapens, R. W., \& Arnold, J. (1986). Economics and management accounting research. In M. Bromwich \& A. Hopwood (Eds.), Research and current issues in management accounting (pp. 78-102). London: Pitman Publishing.

Scapens, R. W., \& Jazayeri, M. (2003). ERP systems and management accounting change: Opportunities or impact? A research note. European Accounting Review, 12(1), 201-233.

Schermann, M., Wiesche, M., \& Kremar, H. (2012). The role of information systems in supporting exploitative and exploratory management control activities. Journal of Management Accounting Research, 24(1), 31-59.

Seddon, P. B., \& Kiew, M. (1994). A partial test and development of DeLone and McLean's model of success. Australasian Journal of Information Systems, 4(1), 90-109.

Silver, M. S., Markus, M. L., \& Beath, C. M. (1995). The information technology interaction model: A foundation for the MBA core course. MIS Quarterly, 19, 361-390.

Sobel, M. E. (1987). Direct and indirect effects in linear structural equation models. Sociological Methods \& Research, 16(1), 155-176.

Stevens, J. P. (2009). Applied multivariate statistics for the social sciences (5th ed.). New York, NY: Routledge.

Taipaleenmäki, J., \& Ikäheimo, S. (2013). On the convergence of management accounting and financial accounting - The role of information technology in accounting change. International Journal of Accounting Information Systems, 14(4), 321-348.

Taylor, S., \& Todd, P. (1995). Assessing IT usage: The role of prior experience. MIS Quarterly, 19(4), 561-570.

Thong, J., \& Yap, C. (1995). CEO characteristics, organizational characteristics and information technology adoption in small businesses. Omega - The International Journal of Management Science, 23(4), 429-442.

Thong, J. Y. L., Yap, C., \& Raman, K. S. (1997). Environments for information systems implementation in small businesses. Journal of Organizational Computing and Electronic Commerce, 7(4), 253-278.

Vasarhelyi, M. A., Kogan, A., \& Tuttle, B. M. (2015). Big data in accounting: An overview. Accounting Horizons, 29(2), 381-396.

Wade, M., \& Hulland, J. (2004). The resource-based view and information systems research: Review, extension, and suggestions for future research. MIS Quarterly, 28(1), 107-142.

Wang, R. Y., \& Strong, D. M. (1996). Beyond accuracy: What data quality means to data consumers? Journal of Management Information Systems, 12(4), 5-33.

Warren, J. D., Moffit, K. C., \& Byrnes, P. (2015). How big data will change accounting. Accounting Horizons, 29(2), 307-407.

Weber, J. (2011). The development of controller tasks: Explaining the nature of controllership and its changes. Journal of Management Control, 22(1), 25-46.

Wilson, R. A., \& Sangster, A. (1992). The automation of accounting practice. Journal of Information Technology, 7(2), 65-75.

Zhao, X., Lynch, J. G., \& Chen, Q. (2010). Reconsidering Baron and Kenny: Myths and truths about mediation analysis. Journal of Consumer Research, 37(2), 197-206.

Publisher's Note Springer Nature remains neutral with regard to jurisdictional claims in published maps and institutional affiliations. 